\title{
Educação, globalizações e cosmopolitismos: novos direitos, novas desigualdades
}

\author{
Carlos Vilar Estêvão \\ Universidade do Minho, Portugal
}

\begin{abstract}
Resumo
Tendo presente o contexto actual onde emergem novas desigualdades e novas injustiças pretende-se articular o processo de globalização com a construção do cosmopolitismo e da justiça social, distinguindo nesta discussão diversas modalidades de cosmopolitismo, nomeadamente a neoliberal e a democrática. Na linha desta última, o autor aprofunda a noção de cosmopoliticidade para vincar não apenas a ideia de universalidade mas também a de dialogicidade global e de politicidade. A partir deste enquadramento analítico, o autor desenvolve as implicações da cosmopoliticidade democrática na educação em geral e na gestão das organizações educativas em particular, no sentido de esta contribuir também para o reforço da justiça global e para o "cultivo da humanidade".
\end{abstract}

Palavras-chave

Cosmopolitismo; Justiça; Educação; Desigualdades

Já há muito que o discurso da crise se instalou entre nós: com a crise do Estado-Providência, assistimos à reformulação das condições do laço social e cívico, uma vez que as instituições de instauração do laço social e da solidariedade, deixam de funcionar. Com a crise económico-financeira, questionam-se as ortodoxias relativas ao funcionamento dos mercados; com a crise do trabalho, alteram-se as formas de relação entre economia e sociedade; com a crise do sujeito, modificam-se os modos de constituição das identidades individuais e colectivas. 
Mercê destas transformações, o tempo actual apresenta-se como um tempo de grande vulnerabilidade social, em que noções como: precariedade e desemprego, emprego temporário, diferenciação, debilidade do movimento social, individualização das relações sociais, desigualdades, insegurança, incerteza, desregulação, fragilidade dos laços comunitários, feminização da pobreza, desqualificação e atomização social demarcam um campo semântico claro de inquietações profundas, apontando para múltiplas formas como muitos são atingidos por um trabalho de verdadeira decomposição, de dessocialização que os vulnerabiliza como seres humanos.

As nossas sociedades desiguais, marcadamente injustas e excludentes, não só não conseguiram cumprir uma das promessas da modernidade que apontava para a gestão controlada das desigualdades através de políticas redistributivas e do pleno emprego, como vêem agora despontar, por novos processos económicos, políticos e culturais, novos sistemas de desigualdades, seja no campo da educação, no da economia, no da cultura ou no da política. Acresce a tudo isto, o escândalo da pobreza que permanece profundamente enraizado na sociedade global actual e que afecta também a relação entre países (de alta e baixa produtividade, por exemplo) e o modo como se integram ou não na economia global, reforçando a convicção de que as desigualdades são também cada vez mais intersocietalmente globais.

Por outro lado, não deixa de ser verdade que hoje se raciocina não tanto em termos de igualdade mas antes em parâmetros de custo e eficácia, de maximização da eficiência mercantil, independentemente dos efeitos de exploração, competição e desigualdade que geram, acolhendo-se pacificamente a ideia, por exemplo, de que é exigência de progresso a separação entre o económico e o social, devendo pugnar-se simultaneamente pela integração económica e pela desintegração social. Assim, o estabelecimento de solidariedades, seja entre indivíduos, seja entre grupos no conjunto social torna-se difícil, cabendo a cada um assumir as responsabilidades pelos encargos assistenciais e de realização pessoal e profissional, ou então delegar no Estado essas mesmas responsabilidades, dentro do slogan: "eficácia para as empresas e a solidariedade para os Estados" (como nos diz Rosanvallon, 1999: 204). O mais grave, porém, é quando se verifica que o próprio Estado está actualmente mais preocupado 
com o financiamento do sistema financeiro do que com a previdência social, em nome, por exemplo, da salvação não apenas do sistema financeiro mas também do sistema económico e produtivo.

A estes e outros desafios as diferentes globalizações tentam dar respostas, umas mais na lógica mercantil, outras na lógica mais democrática ou contra-hegemónica, ambas, no entanto, recorrendo a formas de cosmopolitismo que por vezes esquecem as suas maldades ou enobrecem exageradamente as suas virtudes, nomeadamente em termos de direitos e de combate às novas desigualdades sociais, dentro da nova cartografia do espaço social em que vivemos, induzida, embora não exclusivamente, pela globalização.

\section{Globalização, desigualdades e cosmopolitismos}

A nossa época é caracterizada pelos processos de globalização, que têm sido analisados, do ponto de vista normativo, de muitos modos: uns mais complementares, outros mais contraditórios; uns acentuando a sua bondade, outros a sua malignidade essencial; uns apontando para o efeito do aumento das desigualdades, outros relevando precisamente os seus efeitos positivos em termos de justiça e de igualdade.

Isto significa que o debate sobre a globalização e a sua relação com a desigualdade e o bem-estar dos seres humanos não é linear, apesar das análises que o simplificam: ao omitirem as diferentes concepções e modos discrepantes de medir a desigualdade; ao esquecerem que a melhoria do modo de vida dos cidadãos é muito desigual consoante os países; ao passarem ao lado das novas desigualdades inter e intra-países; ao ignorarem a capacidade de veto dos poderosos sobre a vida dos mais débeis e vulneráveis (fenómeno que Santos apelida de "fascismo social"); ao silenciarem o peso diferenciado do global na explicação das decisões políticas nacionais, uma vez que os factores macroeconómicos, por exemplo, têm impactos diferenciados nos diversos países e regiões, dependendo os seus efeitos da posição global das economias de cada país e de cada região (ver Galbraith, 2007).

Para evitar, então, a simplificação desta questão das desigualdades no mundo actual, há que atender igualmente ao peso diferenciado do global na 
explicação das decisões políticas nacionais, uma vez que a globalização condiciona as decisões sobre o bem-estar dos cidadãos dos diferentes países. Aliás, é cada vez mais consensual a ideia de que as desigualdades nacionais podem ser mais determinadas globalmente do que nacionalmente, devido às crises, movimentos de capitais, etc., o que torna difícil, desde logo, e no dizer de Beck (2006: 39), estabelecer fronteiras entre o nacional e o internacional no campo das desigualdades sociais.

No sentido de esclarecer melhor este ponto, terei em conta sobretudo uma das concepções resultante da investigação deste tópico em Ciências Sociais, que entende a globalização como interconexão ou interdependência mundial cada vez mais extensa, profunda, rápida e ampla em todos os aspectos da vida social contemporânea, com particular incidência ao nível do capital, bens, trabalho, serviços e ideias. Tendo em conta esta compreensão do conceito de globalização, começarei por realçar, como uma questão de facto, a governamentalidade neoliberal, enquanto processo que se tem revelado decididamente parcial no que concerne à justiça, favorecendo os mais favorecidos, num claro contraste com o "princípio da diferença" que Rawls (1993) apontava como caracterizando uma sociedade justa e bem ordenada.

Deixando de lado o pensamento liberal mais moderado que parece preocupar-se, apesar de tudo, com o combate às desigualdades de oportunidades embora não tanto com o combate às desigualdades de resultados, torna-se claro que os adeptos da globalização neoliberalizada não estão preocupados com a ideia de que parte dos benefícios dos sempre ganhadores se faça à custa das perdas dos eternos perdedores (ver Khor, 2000) ou, num plano mais amplo, que a globalização funcione como uma espécie de apartheid (na expressão deste autor) que propicia o neocolonialismo e enfraquece os Estados mais fracos, dentro dos padrões de estratificação global em que alguns Estados, regiões, sociedades e comunidades se apresentam crescentemente mais integrados na nova ordem global enquanto outros, pelo contrário, tendem a ser centrifugados.

Por outro lado, ainda, desde 1970 que alguns economistas têm exigido que a eficiência e a distribuição devem ser consideradas separadamente, interessando, por isso, propor medidas que aumentem a eficiência independentemente dos seus efeitos redistributivos, até porque os 
ganhadores deste jogo podem potencialmente vir a compensar os perdedores. E além disso, uma maior desigualdade pode proporcionar as condições para um crescimento mais rápido. Consequentemente, as políticas públicas devem preocupar-se apenas com os processos de mercado de modo a que estes funcionem correctamente e livremente, até porque os mercados em geral são bons para fornecerem oportunidades de riqueza e outros privilégios a todos, independentemente do país de nascimento, ou da classe, ou do género, ou da etnia. Nesta linha, os ideólogos do globalismo, apresentados como cientistas desinteressados, concluem que dos livres mercados e da mobilidade no trabalho, assim como do capital, pode resultar um mundo mais equitativo, justo e cosmopolita, já não importando até a questão da cidadania uma vez que ela não é central à identidade individual por esta ser entendida como identidade em concorrência. Mesmo a questão da exploração do trabalho e os processos da sua denúncia deixaram de fazer muito sentido na lógica da globalização da acumulação capitalista actual, pois os próprios trabalhadores lutam presentemente, não tanto contra a exploração, mas pela oportunidade de serem explorados pelo capital, ou seja, pela oportunidade de emprego (ver Romão, 2004: 9).

Outro aspecto relevante a sublinhar é que o cosmopolitismo daqui resultante se apresenta, de facto, com roupagens humanistas e socialmente preocupadas, escondendo eventuais efeitos perniciosos decorrentes da sua idealização e do seu imperialismo. Trata-se, enfim, de um cosmopolitismo mercantilizado, consumista, que afina pelo diapasão do próprio cosmopolitismo inerente à lógica de expansão do capital já denunciado por Marx e Stuart Mill. De facto, o capital foi e é essencialmente cosmopolita, o que não invalida o facto de a actividade económica e financeira, desde a produção à investigação, à comercialização e ao consumo se produzir em espaços que são bem reais persistindo o seu carácter eminentemente nacional apesar das operações internacionais a que está sujeita.

Perante este cenário, podemos concluir que a visão cosmopolita mercantilizada é uma visão que apropria uma dimensão sedutora do conceito de cosmopolitismo, embora omitindo, entre outras coisas, a fractura interna que secciona a cidadania, dando o estatuto de cidadãos cosmopolitas sobretudo àqueles que são vencedores nas condições do actual mercado e arredando os outros como "incompetentes" ou "irrelevantes". Mesmo a 
diversidade e o respeito pela diferença, quando são defendidas, não passam de um meio ao serviço da estratégia de mercado, ao serviço, enfim, da governança mundial levada a cabo por agências poderosas (como o Banco Mundial, FMI, OMC). Simultaneamente, o cosmopolitismo mercantilizado vende-nos, através dos seus meios poderosos, não apenas os seus produtos mas também a ordem existente como inevitável.

Em oposição a esta forma de globalização e do cosmopolitismo hegemónico que induz (herdeiro do discurso centrado frequentemente na visão ocidental e elitista do mundo e avesso por vezes à afirmação da realidade do social), os cientistas sociais vêm propondo uma outra globalização, a globalização democrática, e uma outra forma de cosmopolitismo, de sabor Gramsciano: o cosmopolitismo bottom-up, ou, como prefiro dizer, a cosmopoliticidade democrática ${ }^{1}$, construída a partir de baixo (por consensos sobrepostos), que tem a vantagem de valorizar múltiplas cidadanias e poderes, de promover a conversação, de mobilizar as interpretações e aç̧ões políticas de alcance global e de desocultar a fragilidade do ser humano, com ênfase particular não apenas na denúncia da crueldade humana mas também na solidariedade com os outros e na oposição activa a todas as formas de injustiça (Lu, 2000: 244-67).

Este tipo de cosmopolitismo contra-hegemónico, reconhecendo embora que a cidadanização e a democratização também passam pelo Estado, enraíza-se claramente numa outra concepção de democracia: na democracia cosmopolita (ou "cosmopolítica"), que aponta para uma desestatização da cidadania e da democracia, no sentido de as tornar mais abertas aos desafios da globalização, refundando-as num conjunto de valores supra-nacionais (como, por exemplo, nos direitos humanos ${ }^{2}$, como é o caso de Habermas, 2000).

Do lado da sociedade, esta forma de cosmopolitismo, resultado de campos políticos e argumentativos, assume a possibilidade de se construir uma sociedade civil global mais densa, coerente com a ideia de que a consciência global se expande (embora de uma forma não determinista), como é visível, por exemplo: na criação de um novo sentido de pertença e sensibilidade cuja expressão são as novas "formações sociais pós-nacionais" (onde se incluem, por exemplo, os movimentos sociais transnacionais e que ultrapassam as lealdades ao Estado-nação); na protecção dos recursos 
naturais e do meio ambiente; na crescente institucionalização de organizações políticas regionais e mundiais (como a ONU); no compromisso com os direitos humanos. Estes movimentos reafirmam de algum modo a caminhada em direcção, nas palavras de Archibugi (2008), a uma "commonwealth global de cidadãos", importando no entanto não esquecer que as acções destas organizações estão também frequentemente condicionadas pela agenda global mercantilizada e que a maior densidade da sociedade civil global propicia igualmente a criação de novos papéis geopolíticos dos Estados.

\section{Educação no contexto da globalização e justiça}

A noção de globalização tem sido usada para comparar e analisar políticas educativas (Ball, 1998), com ênfase particular nas questões do poder e do conhecimento, na tecnologia, no princípio da igualdade de oportunidades, nas políticas da diferença no interior da educação, entre outros temas.

Por outro lado, a globalização tem vindo a impor um novo mandato aos diferentes países no sentido de, em nome das vantagens competitivas que podem alcançar, terem de redefinir os seus sistemas de ensino e de formação nacionais em termos de qualidade, avaliada segundo padrões internacionais.

Isto exige que os sistemas educacionais se rendam à cultura da performatividade sistémica, através da imposição de indicadores de desempenho como os novos mecanismos de ligação entre o centro que produz a política e as periferias que a põem em prática. Ou seja, enquanto os sistemas educativos eram tradicionalmente locais protegidos por discursos de bem comum, de serviço público, actualmente interessa posicionar a educação como um dos sectores de serviço cruciais para a economia, tal como Tony Blair, referindo-se à aprendizagem, reconheceu numa intervenção pública, nos finais da última década: "a educação é a melhor política económica que nós temos, em 1998".

Claro que não estamos perante uma educação qualquer. Integrada nesse imaginário económico de que estamos a viver numa economia baseada no conhecimento, a educação é sobretudo "conhecimento bytificado" (ou transformado num sistema automático baseado na pronta disponibilização de 
informação e skills), que deve ser retrabalhado como uma mercadoria e contribuir para reforçar os quatro pilares de uma economia sã e competitiva: o da inovação, o das novas tecnologias, o do capital humano e o da dinâmica empresarial. O resto, tal como a política, deve ser remetido para o sótão das "quinquilharias".

Consequentemente, a educação, embalada no discurso da aprendizagem on-line, já não deve ser sensível às origens sociais, políticas e culturais de um país; o que importa são os valores que se encaixem na ética da análise custo-benefício. Na nova retórica política global, onde predomina o mais globalizado e engenhoso dos discursos, que é o discurso da aprendizagem ao longo da vida (e que é, segundo Olssen, 2004, um instrumento da governamentalidade flexível) parece que os sistemas educativos estão a perder a sua função Durkheimiana original de transmitir culturas nacionais e de promover a coesão social, uma vez que se verifica no ensino uma oportunidade comercial que beneficiará claramente com a internacionalização, com a mercantilização do sector escolar e com o reconhecimento global.

Estes processos passam pela criação de escolas de iniciativa empresarial, desburocratizadas, descentralizadas e mais autónomas, escolas internacionais, patrocínios privados, novas parcerias público-privadas, penetração curricular por tendências globais e produção de materiais educativos, com o desenvolvimento de uma pedagogia tecnologicamente mediada, com a reorganização da educação básica e secundária e formação de professores (que corresponde às capacidades e competências requeridas pelos trabalhadores num mundo globalizado), com a mercantilização da educação superior.

No caso específico da aprendizagem, um outro conjunto de estratégias visa reforçar precisamente a sua centralidade tornando-a mais personalizada, fluida e flexível, para produzir, já não tanto cidadãos consumidores mas cidadãos activos. Ou seja, esta personalização, adequada à actual narrativa mestra da economia do conhecimento, teria as mesmas intenções mercantis mas agora através do apelo a uma maior participação. Esta "personalização como pedagogia" para a economia baseada no conhecimento faria avançar, como refere Hartley (2007), a mercantilização da educação colocando-a no coração do processo pedagógico, ao mesmo tempo que reintroduziria os 
mecanismos de consumismo na educação: o indivíduo seria, agora, o produtor-consumidor, que constrói a sociedade.

Concluindo este ponto: a educação sofre os impactos directamente da globalização, mas também indirectamente através de violação dos direitos das crianças, da dívida pública, das crises financeiras, como a actual. Será, então, que mesmo assim poderemos continuar a afirmar que os processos de globalização apenas mudaram a posição relativa dos fenómenos educativos sem alterar a sua substância? Ou que Estados relativamente marginais e frágeis no contexto da globalização devem omitir que a educação é simultaneamente causa e efeito, problema e uma possível solução para a fragilidade em causa?

Tudo o que ficou dito remete-nos para uma outra reflexão que relaciona a educação em tempos de globalização com a questão da justiça. $\mathrm{Na}$ verdade, e independentemente do modo como pensamos a globalização, é um facto que esta está a mudar o modo como argumentamos acerca da justiça (ver Fraser, 2007: 252). Isto significa que a justiça como redistribuição, na linha da justiça económica, e a concepção de justiça como reconhecimento cultural já não podem mais confinar-se ao espaço nacional estatizado e aos seus beneficiários (os cidadãos nacionais).

Neste sentido, uma visão mais global, mais cosmopolita da justiça tem vindo a ser reivindicada, de modo a potenciar não apenas a sua bidimensionalidade (económica e cultural) mas também a dimensão política da representação, isto é, a justiça como paridade de participação, que reivindica o estabelecimento de regras de decisão para dirimir conflitos quer nas vertentes económicas quer culturais, dando voz às minorias, sejam elas povos, minorias ou mulheres... Estamos, então, num outro paradigma que exige uma nova teoria da justiça social ou, na terminologia de Fraser (2007), uma teoria da "justiça democrática pós-westfaliana".

Este novo paradigma impõe à educação novas exigências, designadamente em termos de aprofundamento das suas raízes democráticas e participativas (que de modo algum podem restringir-se ao campo das territorialidades soberanas actuais), pugnando por uma maior simetria estrutural de poder nos diferentes níveis de relações sociais (relações de trabalho, organizações, interacções...) e independentemente das formas em que a desigualdade de poder emerge (exploração, dominação, opressão, 
discriminação, exclusão, marginalização...). Por outro lado, este modo de conceber a justiça reforça também a cosmopoliticidade que a educação deverá ter sempre presente.

\section{Educação cosmopolítica}

Face à descrição anterior sobre o globalismo e o seu cosmopolitismo, reforçados com a emergência de um Estado pós-social minimalista, cada vez mais pós-democrático, em que novas desigualdades assomam perante um claro declínio da esfera pública (ou da sua contaminação pela instrumentalidade e interesses particularísticos) e em que muitas sociedades se transformam em "paraísos divididos", com alguns a procurarem as máximas vantagens das oportunidades oferecidas pelo mercado e outros a sentirem-se cada vez mais periféricos e socialmente irrelevantes, interessame analisar agora como a educação pode ser resgatada à luz da cosmopoliticidade democrática que aqui proponho (veja-se a nota 1).

Em primeiro lugar, uma das intencionalidades da cosmopoliticidade democrática no campo da educação vai no sentido de reteorizar as relações entre escola pública e democracia, revendo, desde logo, a concepção de democracia no mundo global (Reid, 2005). A criação de uma "democracia moral cosmopolita" (que aponta para a possibilidade de cada cidadão poder gozar de cidadanias múltiplas, tendo em conta os contextos que os afectam) deverá, segundo este autor, ser reforçada, obrigando as escolas a que: (i) ofereçam um currículo que desenvolva um determinado número de capacidades acordadas publicamente; (ii) reflictam e dêem expressão a princípios democráticos nas pedagogias, estruturas e processos escolares; (iii) operem em modos que valorizem a diversidade através da construção da comunidade; (iv) não excluam nenhum estudante da participação na vida escolar por razões de diferença; (v) enformem a sua gestão por princípios de democraticidade e participação.

Do mesmo modo, a aprendizagem deve também, neste contexto, ser encarada como um processo de compromisso com o "outro", com a razão e os direitos humanos, numa distribuição igual das oportunidades e perspectivas de vida (Olssen, 2004: 26-27). Com efeito, a aprendizagem deve entender-se, na linha de pensamento deste autor, como um compromisso 
político e social numa comunidade global, constituindo, deste modo, uma forma de participação política e democrática, que deve atender:

i) à igualdade, pois o desenvolvimento de qualquer concepção de justiça democrática, que implica um conceito de aprendizagem, deve incluir a distribuição de recursos e oportunidades de vida;

ii) ao papel do Estado, garantindo, como um direito fundamental, o acesso à educação e ao conhecimento assim como à informação e ao desenvolvimento de capacidades;

iii) ao desenvolvimento da sociedade civil, aqui entendida como o sector autónomo do Estado e da economia, reconhecendo-Ihe o direito ao diálogo, mas também à contestação, ao desafio ou à oposição;

iv) ao papel da educação, como crucial à aprendizagem para a democracia.

Então, a proposta mais congruente para compreender a escola dentro desta contextualização teórica é concebê-la como "organização democrática" e como "arena política", em que se fomentam práticas de democracia deliberativa/comunicativa; em que se questionam os modelos políticos, económicos e sociais de acordo com a justiça que promovem; em que se denunciam as perversões e as injustiças geradas pelos modelos de produção capitalista hegemónicos; em que se desocultam os processos de legitimação das opções culturais dominantes; em que se expõem os tipos dominantes da relação entre poder e conhecimento; em que se alerta para a invasão asfixiante da vida quotidiana e das instituições escolares pela racionalidade científica (Torres, 2008).

Em sentido mais amplo, a educação cosmopolítica deve posicionar-se de modo a potenciar novos direitos, como o da solidariedade (que deve atravessar divisões e hierarquias de linguagem, etnicidade, religião, território, cultura ou cidadania), contrariando o movimento da educação focada no self mais individualizado, ou da educação baseada na criação do "cosmopolita estratégico", do cidadão como jogador económico globalmente orientado, investindo antes na promoção do "self cosmopolita" (ver Mitchell, 2003), participativo, integrando as redes de solidariedades locais e transnacionais de cooperação, mas também de oposição, nunca obscurecendo a importância das relações sociais e da cultura. 
Dentro do mesmo esforço, a educação cosmopolítica pode reforçar a identidade cultural, abrindo-se esta para a análise das reconfigurações de tempo e espaço, para a criação de novas espacialidades e mobilidades, para a consideração de novas racionalidades, desde logo, a racionalidade cosmopolita que é, segundo Santos (2002), aquela que aumenta e densifica as possibilidades de a Humanidade encontrar respostas concretas e adequadas para os seus problemas, partindo da ideia, implícita no conceito de "hermenêutica diatópica", de que todas as culturas são incompletas e que podem, por isso, ser enriquecidas pelo diálogo e pelo confronto com outras culturas.

É esta racionalidade - que eu prefiro caracterizar como cosmopolítica - que, no meu entender, contribuirá para reconfigurar a noção de público como uma "forma de solidariedade social" (Calhoun, 2002: 159) ao mesmo tempo que aumentará a abrangência e a inclusividade da esfera pública, fertilizada pelos valores da democracia cosmopolítica. Também ela permitirá ir além das identidades nacionais territorializadas, apontando antes para a compreensão do laço social como compromisso com os princípios políticos que devem reger uma comunidade política aberta às outras comunidades.

Estamos, consequentemente, num outro registo que coloca a educação numa nova ordem emancipatória, sintonizada com novas exigências em termos de justiça, que considera que os afectados por uma dada estrutura ou instituição social têm o direito moral de ser tratados como sujeitos de justiça. E os afectados não são apenas os situados na territorialidade estatal e condicionados pelo contrato social moderno. $\mathrm{Na}$ reconfiguração do contrato social da modernidade a que vimos assistindo, levada a cabo na tensão entre factores de ordem económica, cultural e política (ver Stoer, Magalhães \& Rodrigues, 2004), as cidadanias emergentes, nomeadamente as culturais, reclamam a sua soberania face ao Estado e marcam as suas diferenças, ao mesmo tempo que invocam outras justiças, para além da estatal.

Neste sentido, as políticas de redistribuição e a cidadania social devem ser repensadas na base de outros territórios (ou instâncias), entre os quais o mundial. Então, a concepção de justiça mais congruente com estas novas exigências é a pós-westfaliana e dialógica a todos os níveis, orientada para a criação de uma nova ordem mundial mais democrática e mais democraticamente controlada. 
Também aqui a educação cosmopolítica deve apoiar a construção do acordo cada vez mais amplo e entrecruzado entre distintos lugares, pela conversação ou interdialogação (ver Appiah, 2004 e Santos, 2004), construindo-se uma universalidade ética concreta, de confluência, que "vem de baixo", cordial e sensível às necessidades das vítimas dos projectos totalizadores. Para tal, a educação deve fomentar a mobilização, entre outros, de dois processos claramente relacionados com a "não dominação" (Olssen, 2004; Olssen, Codd \& Neilli, 2004): a "deliberação" - que implica obter uma decisão que represente um balanço justo entre diferentes pontos de vista - $\mathrm{e}$ a "contestação", entendida como central à deliberação e à liberdade e que substitui a arbitrariedade na tomada de decisão.

\section{Conclusão}

Nesta nova configuração histórica em que se constitui a sociedade global, múltipla e heterogénea, em que se generalizam as relações, os processos e estruturas de dominação e apropriação, antagonismo e integração, como diz lanni (2001: 171), não podemos ficar indiferentes aos desafios epistemológicos, ontológicos e teóricos que dão aos fenómenos sociais uma dimensão global.

Depois, a complexidade da globalização e dos seus impactos exige uma nova cartografia geopolítica que trace os fluxos de efeitos globais e os padrões de imitação, diferença, dominação e subordinação na política e na prática da educação.

Por outro lado, a globalização não supera as desigualdades nem as contradições, antes as recria, as desenvolve a outros níveis e com novos ingredientes e com novas linguagens (por exemplo, através de programas de ajustamento estrutural). Contudo, a solução não está tanto em saber se a globalização deve ou não ser rejeitada, "mas como pode ser regulada em termos de princípios que promovam a justiça social" (MacDonald, \& Midgley, 2007: 11).

É nesta trajectória que devemos reorientar o cosmopolitismo, fazendo não apenas que ele não recubra misérias e decepções, sob o manto do humanitarismo, da segurança, da salvação dos mercados, da securitização do desenvolvimento imposta aos países mais pobres, mas também que 
direccione as lealdades primeiras para o conjunto da Humanidade e não para os Estados, "porque as diferenças entre quem está dentro ou quem está fora [dos Estados] são moralmente irrelevantes", como nos diz Linklater (1998: 56).

Foi neste sentido que propus neste artigo a noção de cosmopoliticidade democrática, visando reorientar o cosmopolitismo ligandoo a formas de contra-globalização, de justiça cognitiva, de combate a rituais de desigualdade e de monopolização de oportunidades, de denúncia de novas formas de regulação da inclusão/exclusão e de limitação da mobilidade social; ligando-o, enfim, a formas de solidariedade social, ainda que desarticule ou afrouxe a sua vinculação aos conceitos de soberania ou de nacionalidade territorializada.

Perante isto, onde situar as funções da educação, considerando que o próprio cidadão crítico actual é um actor algo paradoxal, pois é solidário, mas pouco participativo; crente na justiça equitativa, mas há muito tempo que renunciou à política como meio para transformar o mundo?

A minha proposta desenvolveu-se congruentemente a partir da noção de educação cosmopolítica, investindo numa outra justiça educacional, constituída em alternativa para a construção de uma nova ordem mundial, pela participação socialmente empenhada de cidadãos e cidadãs numa redistribuição e num reconhecimento que se afastem do "modelo da generosidade" e se aproximem do de justiça global.

Não se trata, por conseguinte, de conceber o Outro à nossa imagem e semelhança ou de propor, através do cosmopolitismo, a universalização de direitos e deveres tendo por base a generalização do Outro, isto é, a consideração de que o Outro possui as mesmas características, a mesma racionalidade, os mesmos desejos e as mesmas necessidades que o Eu.

Com a noção de cosmopoliticidade reiteradamente expressa neste trabalho, pretende-se, antes, enfatizar a universalidade concreta, valorizar a diversidade e a interlocução culturais, reconciliar as diferenças, aprofundar o que temos em comum ${ }^{3}$. Aponta-se, por conseguinte, para um universalismo dialógico, de confluência, que tem como objectivo a construção de uma comunidade de comunidades, reconhecendo, como princípio, que todos os indivíduos são de valor moral igual e que devem fazer parte da nossa comunidade de diálogo e atenção. 


\section{Notas}

1 Tenho vindo a utilizar o conceito de cosmopoliticidade democrática no sentido de inscrever a natureza do esprit cosmopolite (que transcende o particularismo regional, quer este seja definido territorialmente, culturalmente, linguisticamente ou racialmente) e a dimensão ético-política democrática, dialecticamente construída. Por outras palavras, com esta expressão pretendo ressaltar, recolhendo os contributos de Daniele Archibugi e de Paulo Freire, um campo de força global, de natureza ética, cultural e política, construído e reconstruído em tensão dialógica, a partir de redes e consensos entrecruzados, que não respeitam mais a distinção centro-periferia, mas que apontam antes para outra espacialização da política e dos direitos humanos e também para formas de redistribuição social mais globais.

2 Pese embora a crítica de a solidariedade dos cidadãos mundiais, fundada apenas no universalismo moral dos direitos humanos, ser demasiadamente fraca para gerar a coesão requerida para a implementação de políticas globais, como nos diz Cheah (2006: 7)

3 Para outros autores, nomeadamente Casa-Nova (2008: 93), "tão ou mais importante do que tentar perceber o que une as diferentes culturas para tornar possível o diálogo, é compreender o que as separa." De acordo com a mesma autora, "O desafio teórico consiste em de como, a partir da compreensão da (in)comensurabilidade das diferenças, tornar possível a construção de diálogos entre diferentes."

\section{Referências}

APPIAH, K. Anthony (2004). Ciudadanos del mundo. In Matthew J. Gibney (Ed.), La Globalización de los Derechos Humanos. Barcelona: Crítica, pp.197-232.

ARCHIBUGI, Daniele (2008). The Global Commonwealth of Citizens. Toward Cosmopolitan Democracy. Princeton: Princeton University Press.

BALL, Stephen (1998). Big policies/small world: an introduction to international perspectives in education policy. Comparative Education, 34(2), pp. 119-130.

BECK, Ulrich (2006). Cosmopolitan Vision. Cambridge: Polity Press.

CALHOUN, Craig (2002). Imagining solidarity: cosmopolitanism, constitutional patriotism and the public sphere. Public Culture, 14 (1), pp.147-171.

CASA-NOVA, Maria José (2008). Etnografia e Produção de Conhecimento. Reflexões Críticas a partir de uma Investigação com Ciganos. Lisboa: ACIDI.

CHEAH, Pheng (2006). Inhuman Conditions. Cambridge: Harvard University Press.

FRASER, Nancy (2007). Reframing justice in a globalizing world. In D. Held \& A. Kaya (Eds.), Global Inequality. Cambridge: Polity Press, pp. 252-272.

GALBRAITH, Gareth (2007). Global inequality and global macro economics. In D. Held \& A. Kaya (Eds.), Global Inequality. Cambridge: Polity Press, pp. 148-175.

HABERMAS, Jurgen (2000). Après l'État-Nation. Paris: Fayard. 
HARTLEY, David (2007). Personalisation: the emerging revised code of education? Oxford Review of Education, 33 (5), pp. 629Å]642.

KHOR, Martin (2000). Discurso na Sessão de Abertura do Fórum do Milénio, na Assembleia Geral das Nações Unidas, em 22 Maio de 2000.

IANNI, Octávio (2001). A Sociedade Global. Rio: Civilização brasileira.

LINKLATER, Andrew (1998). The Transformation of Political Community : Ethical Foundations of the Post-Westphalian Era. Cambridge: Polity Press.

LU, Catherine (2000). The one and many faces of cosmopolitanism". Journal of Political Philosophy, vol. 8, oㅡ 2, June, pp. 244-67.

MACDONALD, Frederick \& MIDGLEY, James (2007). Introduction: globalization, social justice, and social welfare. Journal of Sociology \& Social Welfare, Junho, vol. XXXIV, no 2, pp. 9-15.

MITCHELL, Katharyne (2003). Educating the national citizen in neoliberal times: from the multicultural self to the strategic cosmopolitan. Transactions of the Institute of British Geographers 28, (4), pp.387-403.

OLSSEN, Mark (2004). Neoliberalism, globalisation, democracy: challenges for education. In Globalisation, Societies and Education, vol.2, July, pp. 231-275 [em linha]. [Acedido em 8 de Outubro de 2008, disponível em http://www.informaworld.com/smpp/section?content=a713620757\&fulltext=713 2409].

OLSSEN, Mark; CODD, John \& O’NEILLI, Anne-Marie (2004). Education Policy. Globalization, Citizenship \& Democracy. London: Sage.

RAWLS, John (1993). Uma Teoria da Justiça. Lisboa: Editorial Presença.

REID, Alan (2005). Rethinking the democratic purposes of public schooling in a globalizing world. In M. Apple, J. Kenway \& M. Singh. (Eds.), Globalising Education: Policies, Pedagogies and Politics. New York: Peter Lang, pp.281296.

ROMÃO, José Eustáquio (2004). Prefácio à edição brasileira. In Stephen Stoer, António Magalhães \& David Rodrigues. Os Lugares da Exclusão Social. Um Dispositivo de Diferenciação Pedagógica. S. Paulo: Cortez Editora, pp. 5-12.

ROSANVALLON, Pierre (1999). La Nouvelle Question Sociale: Repenser l'ÉtatProvidence. Paris: Seuil.

SANTOS, Boaventura (2002). Para uma sociologia das ausências e uma sociologia das emergências. Revista Crítica de Ciências Sociais, 63, pp. 237-280.

SANTOS, Boaventura Sousa (2004). Do pós-moderno ao pós-colonial: e para além de um e outro. Conferência de Abertura do VII Congresso Luso-Afro-Brasileiro de Ciências Sociais. Coimbra, 16 de Setembro de 2004.

STOER, Stephen; MAGALHÃES, António \& RODRIGUES, David (2004). Os Lugares da Exclusão Social. Um Dispositivo de Diferenciação Pedagógica. S. Paulo: Cortez Editora.

TORRES, Santomé, J. (2008). Diversidad cultural y contenidos escolares. Revista de Educación, 345. Enero-Abril, pp. 83-110. 
EDUCATION, GLOBALISATIONS AND COSMOPOLITANISMS: NEW RIGHTS, NEW INEQUALITIES

Abstract

Considering the actual context where new inequalities and new injustices emerge, I aim to articulate the process of globalisation with the construction of cosmopolitanism and social justice as I distinguish in this discussion various types of cosmopolitanism such as the neoliberal and democratic types. Within the latter, I deepen the notion of cosmopoliticity in order to stress the idea of universality as well as global dialogicity and politicity. The end of this essay explains how democratic cosmopoliticity influences education and educational administration so that it contributes to a stronger global justice and the "cultivating humanity".

Keywords

Cosmopolitanism; Justice; Education; Inequalities 


\section{ÉDUCATION, GLOBALISATIONS ET COSMOPOLITISMES. NOUVEAUX DROITS, NOUVELLES INÉGALITÉS}

Résumé

Vu le contexte actuel où émergent de nouvelles inégalités et de nouvelles injustices, on prétend articuler le processus de globalisation avec la construction du cosmopolitisme et de la justice sociale, en distinguant, dans cette discussion, les diverses modalités de cosmopolitisme, notamment la néolibérale et la démocratique. Dans la ligne d'analyse de cette dernière modalité, l'auteur approfondit la notion de cosmopoliticité pour friser non seulement l'idée d'universalité mais aussi celle de dialogicité globale et de politicité. À partir de cet encadrement analytique, l'auteur développe les implications de la cosmopoliticité démocratique dans l'éducation en général et dans la géstion des organisations éducatives en particulier, tenant en compte le sens que celle-ci acquière, aussi, quand on parle d'une contribution au renforcement de la justice globale et de la "cultivation de l'humanité".

Mots-clé

Cosmopolitisme; Justice; Éducation; Inégalités

Recebido em Junho/2009

Aceite para publicação em Setembro/2009 